Saša Paunović1, Dušan Starčević ${ }^{2}$, Lazar Nešić ${ }^{3}$,

${ }^{1}$ Ministry of Interior, Republic of Serbia

2 University of Belgrade, Faculty of Organizational Sciences

${ }^{3}$ Ministry of Interior, Republic of Serbia

\title{
Identity Management and Witness Protection System
}

UDK: 005:343.143

DOI: 10.7595/management.fon.2012.0038

\begin{abstract}
The protection of participants in criminal proceedings is one of the most important tools for prosecution of war crimes and organized crime cases. The paper presents the basic characteristics and the importance of implementing the Program of protection in criminal proceedings, with emphasis on the protection system and management of identity. Special attention was paid to challenges facing the protection system in criminal proceedings and the management of identities, which are caused by the use of biometric identification procedures. The closing part of the paper presents possible improvements in identity management in criminal proceedings.
\end{abstract}

Keywords: identity management, witness protection system, witness protection measures, biometrics, change of identity.

\section{Introduction}

There is no doubt that terrorism and organized crime are recognized as the biggest challenges of the modern age, and a serious threat for safety of any country, considering that they undermine the very core of democracy, and basic civilisation values and inflict severe damage to the society and the state (Douglas, 2004). The additional severity of these forms of crime, especially considering revealing of the organizers and principals, gives a transnational character to organized crime and terrorism, which doesn't recognize geographical and national differences. In this view it is necessary to organize a common approach for all countries in the region and in the world in order to efficiently combat criminals, because they easily avoid responsibility in the countries they live in. Court practice, not only in the European but in the American courts as well, has confirmed that in cases considering organized crime, the most efficient weapon is the existence of a witness that comes from that criminal organisation since he can help in revealing the organization's methods, hierarchy, the way they act, the way they are financed and can provide relevant evidence for the trial (Douglas, 2004 \& US Marshal Service, 2012). Therefore it is necessary to establish an adequate mechanism which will contain special measures for an effective protection of all participants in the trial process and the members of their close family. The UN is obliged to act according to internationally ratified documents, but first of all, according to the UN Convention regulations against internationally organized crime and the Roman statute of The International Criminal Court (llić, 2006). After the ratification of these documents most countries have developed and enacted an appropriate legal framework which has created legal preconditions for the effective implementation and application of protection systems in the criminal procedure. In case of the Republic of Serbia, after the Law on the protection program of participants in criminal proceedings which is in the frame of Ministry of Interior of Republic of Serbia, a specialized unit is formed whose task is to implement the national program of protection.

The Second and Third chapters will elaborate some elements of the implementation of the Witness protection programme of participants in a criminal trial process with a short review on law regulations describing proper measures for witness protection in the criminal trial process. The Fourth chapter is based on identity management and problems related to the change of a witness's identity and the covering of identity and property data. The Fifth section of this work will describe the relationship between the identity management and biometrics technologies for person identification. The Sixth chapter is dedicated to the challenges of the witness protection system in criminal trial process and identity management, which are results of applying biometrics technologies in the process of identification (Dandurand \& Farr, 2010). The end of this paper deals with new possible improvements regarding identity management and the system of the witness protection program. 


\section{Programme for protecting participants in criminal proceedings and legal regulations}

From the point of the criminal theory and practice, the implementation of the Witness Protection Programme has a significant impact on confronting organized and transnational organized crime, especially in the areas of timely provision of evidence. It is known that people rarely appear as witnesses in the proceedings, because they fear for their safety and the safety of their families, even though many of them were eyewitnesses to crimes committed by organized criminal groups. Implementing security in the framework of protection in criminal proceedings leads to a greater interest of the citizens to testify, since they are guaranteed protection and personal security (Douglas, 2004 \& US Marshal Service, 2012). The status of a protected person inside the programme can be obtained only if a statement is given, i.e., information is provided without which it would be impossible or considerably more difficult to prove crimes against constitution and safety; humanity and international law; as well as crimes with the elements of organized crime (Law, 2005).

At the international level, the issue of witness protection is regulated by treaties on the multilateral and bilateral levels. The most important treaties of international law governing this issue are:

- The UN Convention against Transnational Organized Crime with additional protocols (UNCATOC, 2003).

- Statute of International Criminal Court (ICC, 2002),

- Statute of the International Criminal Tribunal for the Former Yugoslavia which was established under the UN Security Council resolution no. 827 of 25 May 1993. (ICTY,1993).

At the European level it was adopted by the European Convention on Mutual Assistance in Criminal Matters (Criminal Law Convention on Corruption,1999) and the Council of Europe Recommendation on the intimidation of witnesses and the right to counsel (Recommendation, 1997). Also, the Council has made the following decisions:

- Recommendations on domestic violence (Recommendation, 1984);

- Recommendation on the protection and assistance to the victims (Recommendation, 1987);

- Recommendation regarding sexual exploitation and exposure of children and youth to pornography, prostitution and trafficking (Recommendation, 1991);

- Recommendations on penal policy in Europe during the change (Recommendation, 1996), and

- Recommendation on witness protection and collaborators (Recommendation, 2005).

The European approach to the witnesses protection differs from the approach applied in the USA and South America because it is much broader and often includes support (economic, social, psychological, etc.), and not only the means for protecting witnesses. Legislation at the national level, related to the protection of witnesses is different and varies from country to country. Some countries have shown a very detailed legislation for the witness protection (Slovakia, Serbia, Australia, Canada), while others use general provisions of the Criminal Code and the Criminal Procedure (England, Scotland, France). There are some countries that are only now adopting a law on the protection programme and which rarely have people who are willing to act as witnesses (Finland). However, there are cases that some countries have witnesses and have no choice but to protect witnesses, despite the lack of legislation and other legal acts (Greece, Guatemala, Spain) (Dandurand \& Farr, 2010). In most Eastern European countries laws on witness protection at the national level are similar to and originate from the Slovakian legislation (UN, 2008). The law generally involves an independent body (board, Commission), which decides on the admission to the witness protection program, whereas the police force is responsible for enforcing safety measures and the risk assessment.

As for the Serbian legislation, the Law on protection programme for participants in criminal proceedings came into force on January 1, 2006 and it regulates the conditions and procedures for providing protection and assistance to all parties involved in a criminal act, as well as all parties close to them (Law, 2005). Protection under this Act applies only to those persons whose personal safety or the safety of their families is at risk due to their testimonial in the preliminary and criminal procedure, and ensures the implementation of various measures envisaged by this law. Such protection can be applied practically to all persons who are participants in the criminal proceedings and exposed to real danger due to giving evidence or due to providing relevant information. More specifically, witness protection is applied to the witness, victim and the witness assistant, and the suspect or defendant, expert and specialist, and can be applied to a person close to the mentioned entities. The person is, of course, an immediate family member (spouse, child, parent, sibling), or other person so designated by a protected witness - provided that carrying out threats would indeed put the protected witness under serious pressure. Protection can be applied to the protected person before, 
during and after the finalization of criminal proceedings, and all authorities and persons who participate in it must proceed with particular urgency. Information relating to the Protection Programme is an official secret and must not be revealed by anyone who is familiar with them.

\section{Measures to protect participants in criminal proceedings}

The process of determining the measures of protection should involve the proportionality between the nature of protection measures and the severity of intimidation the witness was exposed to. They must be applied to witnesses and victims who are in need of protection longer than the length of proceedings in which they must testify. Measures are determined because of the risk to the safety of these individuals or members of their families (llic, 2006 \& Law, 2005 \& Recommendation, 2005). The implemented witness protection measures vary from state to state. Most states are able to offer similar protection measures depending on the specifics of the case findings and the risk assessment. Witness protection programmes include physical protection, identity change, relocation, financial support, and various other types of support (psychological, legal, health, etc.). Some programmes are able to offer money in exchange for physical protection, so the protected person must use their own precautions (Italy). In Serbia, based on Article 14 of Law on protection programme for participants in criminal proceedings the following measures shall be applied: physical protection of person and property, change of residence or moving to another reformatory institution, concealment of identity and ownership data, as well as the change of identity. It is envisaged that during the implementation of protection one or more measures can be applied, and that the change of identity can only be applied when the witness protection cannot be implemented through other protection measures. In further text the measures to conceal the identity and ownership data, measures of changing identity and the field of application of biometric identification methods in this field will be discussed in more detail.

\section{Identity management in the protection system of participants in criminal proceedings}

\subsection{Concealing identity and information about ownership}

The measure of concealing identity and information about ownership shall comprise the creation and the use of personal documents and documents related to the property of the witness, which contain temporarily changed original data. This measure is applied when it is necessary to eliminate the risk of a possible situation in which the protected person could be found (Law, 2005). However, this type of measure shall not result in the change of original contents of the official records. It means that during the application of this type of measure the original data on the protected person that is kept in the official records remain unchanged. These are records of the personal data which represent privacy, integrity, personal and family life and other personal rights in connection with the identified person or the person that can be identified (llic, 2006 \& Law, 2005 \& Recommendation, 2005). This type of measure involves using the altered identity documents or property documents where the protected person has limited freedom in using documents with temporarily changed personal data. The limitation also includes the limitation in legal transactions which may influence the third party. The main problem is the fact that the protected person might need to conclude legal transaction with a third party, which also affects the third party. In that situation the protected person must get consent from the Protection Unit, but if that is not the case, the protected person has the right to nominate a proxy who will conclude the legal transaction in his or her real name and for his or her account. But, in the latter case the consent from the Protection unit is also required. The selection of solutions depends on risk assessment to which the protected person may be exposed if the legal work is concluded using the documents with original data (llic, 2006).

\subsection{Change of identity}

Changing the identity is a specific measure that shall be applied only when other measures cannot provide adequate witness protection. This measure consists of creating a new "living legend (history)," of a witness, giving them new identity documents, and relocating them to a new environment, which prevents third parties to trace their original identity. However, in these situations a witness must be given the opportunity to keep their existing personal status - marital status, profession, religion and other life activities after the change of identity. One of the basic principles of the change in identity are the protection and the safety that must 
be achieved without adverse consequences to witnesses, as guaranteed in terms of human rights and in terms of moral values. In addition, the client must be provided with economic, social, health, and legal aid, as well as all other necessary support during their adaptation to the new identity, all in order to protect them against recidivism and reintegration into criminal activities (Iliic, 2006 \& UN, 2008).

In case of identity change the number of changed details varies from country to country. In some countries such as the Netherlands, Great Britain and the United States, it involves changing only the essential details - personal details (name and surname), while in other countries (Italy, Germany, Slovakia, Austria) it involves changing other data, such as - the place and date of birth, parents' names, etc. When changing the identity it is very important that the link between the old and the new identity cannot be established. This ensures the provision of maximum protection and safety. Bearing in mind the fact that physical parameters are mostly used for identification, in some countries the use of plastic surgery is allowed (Poland and the Baltic countries). So, in addition to data being changed in the documents and other public papers, the change of identity can include the change of physical, or some biometric traits, which is achieved by facial plastic surgery or removal of other physical signs of recognition, such as moles, birth marks and tattoos. The change of physical traits (plastic surgery) is usually granted after the completion of judicial proceedings in which the witness testified, and when the final verdict is passed.

When changing the identity, the witness is required to give all the documents on their original identity to the unit that carries out the witness protection programme. This is necessary for security reasons (to prevent finding the original, the real identity), and to prevent the abuse of different identities. In this way protected persons receive new identity documents, which are regularly issued in accordance with legal norms and with all degrees of protection (photograph, signature, biometric data, etc). Here it is also important to point out that in some countries all documents that contain personal information have to be changed, while in others, however, only those documents that are essential for a new identity are changed (US Marshal Service, 2012), (Dandurand \& Farr, 2010).

The type and the number of documents provided to witnesses vary from country to country, but the following are most common:

1. Passport;

2. Identity card;

3. Identification number:

4. Medical records or health history;

5. The tax code;

6. Certificate of Citizenship;

7. Driver's license;

8. Registration card;

9. Birth certificate;

10. Citizenship by right of birth;

11. Proof of educational qualification;

12. Evidence of graduate courses and professional training.

When issuing new documents for a protected person, it is very important to keep separate records of such documents, and those documents are kept in permanent records. Therefore, after changing the identity the Protection Unit preserves, approves and monitors the access to initial data about the identity of a protected person and takes care of all statutory and other rights and obligations that are related to the real identity of a protected person. In the case of the Republic of Serbia, according to the Law on protection programme for participants in criminal proceedings, the issuance of the so-called "undercover" personal documents is no different from the original procedure of issuing personal documents. It is important to emphasize that the data in the "undercover" personal document or documents must not be identical to another person's data. It should be noted that the production and use of documents executed in accordance with this Act to implement the measures to conceal the identity and the ownership and the identity change of a protected person is not a crime. The Protection Unit is a body that is the only link between the new identity and the records holding the original data on a protected person, i.e. their real identity (Ilic, 2006).

In the Republic of Serbia, according to Article 23 of Law on protection programme for participants in criminal proceedings, the protected person is to participate in a criminal proceeding with the original identity, as a suspect, defendant, witness collaborator, witness, victim, expert or professional person summoned to 
court in connection with criminal offenses committed before the change of identity. For other proceedings before a court or government authority where it is necessary to use the original identity, a protected person may participate only with the consent of the Protection Unit. If the Unit does not give consent, a protected person exercises their rights in proceedings through a representative. If, after the change of identity, the protected person commits an offense, the Unit is obliged to notify a competent public prosecutor and the Commission for implementing the Protection Programme. Calling the protected person is done through the Unit, which provides for his arrival. Depending on where the criminal act is done, the public prosecutor will decide how it will proceed (to postpone prosecution or to raise the appropriate criminal proceedings). Committing a crime may be grounds for cancelling the Witness Protection Programme (llic, 2006 \& Law, 2005).

\section{Identity management and biometric identification systems}

Identity, which was discussed in the previous section, is an important issue of a modern society. Serious safety requirements forced experts to explore ways in which the biometric data can be used to identify individuals, as part of the identity management. Biometric identification is based on technologies which analyze human physical characteristics and behaviour. Physical characteristics include, for example, fingerprints, retina and iris, and facial features; and behavioural characteristics include, for example, signature or the dynamics of walking. But, it is sometimes difficult to differentiate between physical characteristics and behavioural characteristics, like, for example, voice. Some authors believe that voice is a mixture of physical characteristics and behavioural characteristics, so which biometric traits share both physical characteristics and behavioural characteristics remains open for discussion (Dessimoz, 2007).

The method of biometric identification is a method for identifying based on unique biological features. The most important institutions in the world dealing with biometrics and identity management are shown in Figure 1 (Biometrics, 2012).

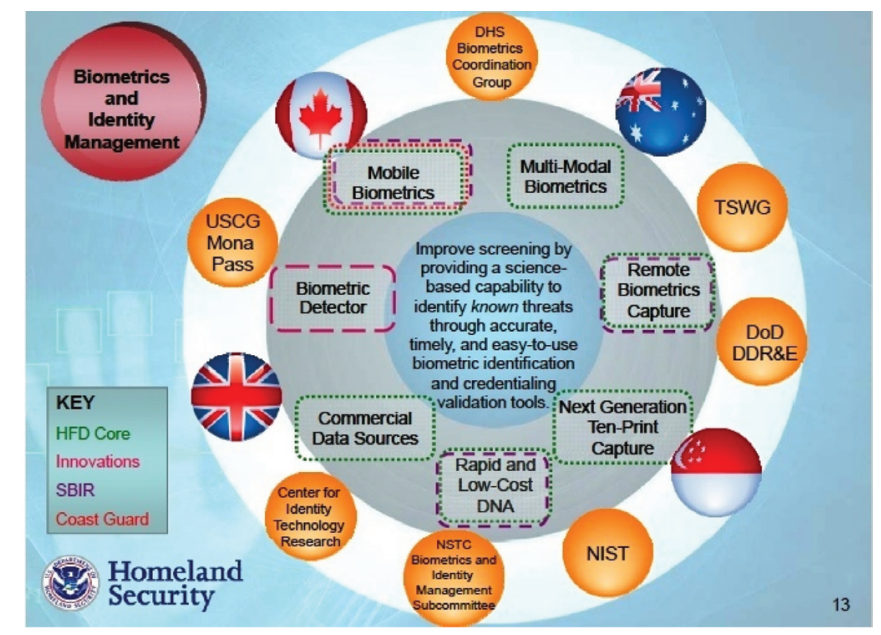

Fig.1: Biometrics and identity management, (Biometrics, 2012).

The term identification comes from the Latin word "identificare" which means identity determination. In modern society it represents a relationship between personal data and the person. Biometric identification methods, in social economic terms, are based on measuring a person's specific certain characteristics with the purpose of confirming their identity. Biometric identification has been improving and is being implemented in different systems, but there is a difference in biometric system application from the point of users and from the point of system in which they are being installed. From the user's perspective, because they are sensitive data, it is important that the action of the state and the autonomy of the individual are proportional, as well as that the system interferes with the users' activities connected with the process of identification as less as possible. Also, how the system works and how high are the costs of acquisition and maintenance is very important for the user. Each implementation requires compromise in order that an optimal and functional system be obtained (Paunovic \& Starcevic, 2011). 
Biometric features have many advantages because they cannot be lost or forgotten. Biometric systems are faster and more convenient to use, cheaper to implement and manage, and they are safer than the traditional ones. Such biometric systems are already used at border crossings as automated systems for transferring citizens across borders. In many countries an ID document contains some kind of biometric data. Since 2005 a large number of European countries have been using biometric passports. International civil air organization (ICAO) has issued a special recommendation for the use of biometric passports which must contain a facial image and a fingerprint, or even an iris scan, as means of biometric identification. The development of biometrics offers a great hope for ensuring the protection of one's identity and privacy. Biometric technologies also have great potential for improving the safety and security of citizens. The application of biometric technology can be found in many human activities such as travel documents (visas, passports), border control, police service, controlling access to certain locations, e-banking, etc. The rapid development of technology has increased the need for reliable methods of identifying people. Biometric technologies are increasingly becoming our reality. Now citizens come into contact with biometric applications in different situations, especially in international travel. Today the world is faced with the threat of terrorist networks and groups which tend to threaten the country's economy and disrupt people's lives. To protect individuals, families and normal functioning of the community, security and other government authorities in each country are trying to detect and prevent terrorism. The fear of terrorist attacks has initiated compulsory identification documents and travel documents which include biometric data (compulsory digital image, and optional fingerprint fingerprints, an iris scan, etc.). That is a logical choice, because the biometric identity cannot be falsified or copied (Paunovic \& Starcevic, 2011). However, this feature of biometric identity opens up new challenges in the witness protection system!

\section{Challenges for the protection system of participants in criminal acts and identity management}

The protection program, as the most successful means in the fight against organised crime and war criminals, is applied as the last resort, in circumstances where no other effective measures can protect those persons who are prepared to stand as witnesses in court. Individuals who enter the protection program are predominantly given secret or new identities which they will use while they are part of the programme. The change of identity and location provides these individuals with the opportunity for a new beginning. However, this also brings about a need for them to change their lifestyle as well as limitations or restrictions to basic personal liberties, including movement, communication and employment. There are further, more serious implications and psychological consequences for individuals under the protection programme. They are expected to never recall their past as well as deal with the constant pressures of adjustment to a new living environment and being able to deal with questions and enquiries from others. With this in mind, these individuals must be given maximum psychological support in order to ease their adaptation and social integration under their new identity. Under the new identity, the subject must change all habits and discontinue relationships and communication with friends, colleagues and family. This is no easy feat, given the criminal past and affiliations of these individuals, especially as they would have to sacrifice their social and financial status built up over years of involvement in criminal activities (Dandurand \& Farr, 2010), (UN, 2008).

The process of identity change must be executed in line with the law and the subjects under the programme must be enabled to use their existing knowledge, experience and expertise in their new life. However, for people with certain expertise, doing so could compromise them and lead to the uncovering of their original identity. Examples of these include public figures, lawyers, and sports people (llic, 2006), (Dandurand \& Farr, 2010), (UN, 2008). In these situations, the witness must be enabled to change their career or acquire new skills or qualifications, without fraudulent intervention, such as falsifying diplomas or certificates. The protection programme must therefore facilitate the educational needs to enable the person to acquire any necessary qualifications. For instance, they cannot simply be given a doctor's qualification, but must be enabled to study medicine and develop their career in that field. A new career path must be chosen so that employment and financial independence are achieved as soon as possible. In some cases, during the protection programme, a need may arise, whereby the person under protection requires a multiple identity change. These cases normally involve individuals who fail to adapt to a new environment and way of life including being unable to cope with various barriers, such as cultural, language barriers or the lack of communication with friends or family. As a result, the person may choose to opt out of the protection programme, which they voluntarily joined. If, in the future, the person's safety, or the safety of those close to them becomes compromised, they may choose to re-enter the program, in which case they must be given an en- 
tirely new identity. Similarly, if the person's current identity is uncovered as fake, they will be given a different, new identity. The duration of any protection programme can span over years or decades and as such, the new identity can be carried forward into future generations.

Advances in technology and hence methods of entering and maintaining information and records bring great new challenges to the Protection Programme, particularly the process of changing identities and the creation of legends, for the protected persons. Previously, when paper based records were solely used, without any electronic data such as digital photographs, implementation and management of new identity profiles was considerably simpler to do. Today, every change and transaction in electronic databases is audited. In addition, the ability to gain access and scan over electronic data such as digital photographs highlights a vulnerability whereby a link between two or more identities could be uncovered for any individual in the system, including that person's original, true identity. Centralisation of databases for documents with the appropriate level of protection in the form of hologram, which is standardised across all governing bodies, from central government to local governments, adds additional pressure the protection system must cope with.

It must also be noted that whilst offering numerous benefits to its users, today's widespread technology and in particular the use of the Internet presents another challenge to the witness protection system. Whilst persons under the witness protection programme cannot be prevented from using these technologies as it would violate their basic rights, the use of the Internet by these individuals, especially the use of social media networks (Facebook, twitter, etc) creates a potential danger for their true identity to be uncovered, compromising their safety. Alongside the benefits created by the use of biometric data in identity documents as an effective counter terrorism measure, this technology also represents additional challenges for the witness protection programme, when concealing or creating a new identity for an individual that enters the programme.

The greatest challenge here is that the nature of biometric information is different from an other personal information used to identify an individual, in that it cannot be changed. Namely, if a given person has had their biometric data taken, prior to entering the protection programme, when they enter the programme and are issued a new identity, their biometric data will have already been stored on the appropriate database, and linked to their previous identity. Additionally, biometric identification highlights a further obstacle whereby travel restrictions are automatically introduced to persons under the protection programme. More precisely, persons under the programme, who have prior to entering the programme travelled to countries (USA, United Kingdom etc) where Visa acquisition mandates submission of biometric identifiers will automatically not be able to travel to these countries under their new identities. Clearly, given that biometric checks are carried out at border control points, their new identity would automatically be linked to their previous identity, through the matching biometric identifiers. As a result, the freedom of movement which is protected by the European Convention for the protection of human rights is automatically violated. Other restrictions in circumstances described above include the ability to make payments, withdraw money or carry out similar financial transactions whereby their identity needs to be established through their personal identification documents. In cases where changing a person's details is not sufficient, it is also possible to make alterations to one's physical alterations in order to successfully and effectively change their identity. This way, the person's face will have a new physical appearance. In contrast to other measures taken to change one's identity, alteration of physical features is a more permanent measure as the person would retain their new look even after exiting the protection programme.

It should also be noted that restrictions imposed by changing a protected person's identity are by no means limited to the public sector. Firms operating in the private sector also make use of databases to maintain biometric identification records, among them banks, or insurance companies. For instance, prior to completing a financial transaction, identification might be made using a digital photograph of the person. Following alterations of one's facial features, it will no longer be possible for that person to be positively identified as the rightful user of the bank account and they will no longer be authorised to make any transactions (UN, 2008). In addition, some organisations, such as insurance groups go a step further in that they require DNA samples to be provided as a means of identification, before considering any payouts if a claim is made. Clearly, this highlights a similar issue, whereby a person with a new identity would still identify with their previous one, as their DNA would be unchanged.

Despite the challenges faced in the process of identity change, in certain situations it is the only way of providing sufficient and effective protection. Should any person who is offered the protection programme refuse to enter it, the only other alternative is extensive isolation, which could have serious psychological implications. 
As biometric identification solutions continue to gain momentum and their implementation becomes more common, their negative implications for the witness protection programme become increasingly serious. In contrast, there is no agreement or certainty with respect to a solution to these problems which represents the greatest future threat to the witness protection programme.

\section{Improvements to witness protection measures}

In order to improve system of witness protection we are going to use a multidisciplinary approach in the witness protection programme, which besides informatics discipline includes organizational, legal, psychological and sociological disciplines. It is important to mention that there is no formal agreement on laws which surround the protection of witnesses on a World scale, nor are these laws standardised within Europe. Countries which provide witness protection programmes should have standardised protocols on a national level to enable effective communication and collaboration between different organisations, involved in witness protection. In this respect, it is paramount to establish and define responsibilities of governing bodies as well as the responsibilities of other, non-government organisations which are often involved in approaching people, prior to entering them into the witness protection programme.

During the protection programme, the subjects are exposed to various forms of psychological stress. It is therefore necessary to establish active psychological support and education, as well as an appropriate level of trust between the subject and those providing the protection. This helps identify and prevent any potential problems which may arise. In this regard, it is necessary to cooperate with specialist psychological experts, international organisations ICTY, and in due course form support teams that will provide psychological help to the subjects as well as members of the protection unit personnel. Each protection unit should have a person of required competencies, a psychiatrist and a psychologist. It should be emphasised that different approaches should be taken when dealing with war criminals and those who committed organised crime offences. In cases involving the prosecution of war criminals, the witness must be given psychological support in the lead up to the court hearing as this is a crucial time, when the witness is likely to experience great anxiety, knowing that they must come face to face with the accused, in the courtroom. The accused will often be a person well known to the witness (before the war, a family friend, or even a relative). In organised crime cases, witnesses are likely to be faced with challenges surrounding the necessary changes to their lifestyle, restrictions to their movement and interaction within social circles. There are also issues to do with the person's likely tendency towards committing criminal offences, drug and alcohol abuse. When dealing with any of these addictions, the subject is advised to go through a rehabilitation process and any antisocial tendencies are addressed by members of the protection unit and other professionals, helping the subject reintegrate socially. Social re-integration is also necessary in cases where a subject was previously isolated for extended periods of time due to difficulties in adaptation to a new environment or their new identity. Given the above, it is necessary to assign delegates to team leaders as well as other members of the protection units who will offer guidance with respect to appropriate behaviour and communication with the witness.

Alongside the legal and psychological issues, one key issue is of a technological nature, relating to modern methods of communication and social interaction via social network sites and other Internet based tools. It is important that prior to making use, or continuing to use the Internet communication, the witness is thoroughly and continuously educated on how to do it safely, and securely. Following the creation and issuing of the new identity and the associated documents, separate audit trails must be kept, to track the origin of the identity. This is done by the assigned protection unit. In addition, the unit is responsible as to any other aspects, rights or statuses associated with the witness while they assumed their previous identity. They are also responsible for producing biometric identification artefacts as well as governing biometric data associated with all persons under the protection programme.

The protection unit is the only government body which maintains the association between a person's new identity and their original identity. The only other link between the two identities is the person's physical, biometric attributes, which cannot be changed and stay with the person for as long as they are alive (Fig. 2). 


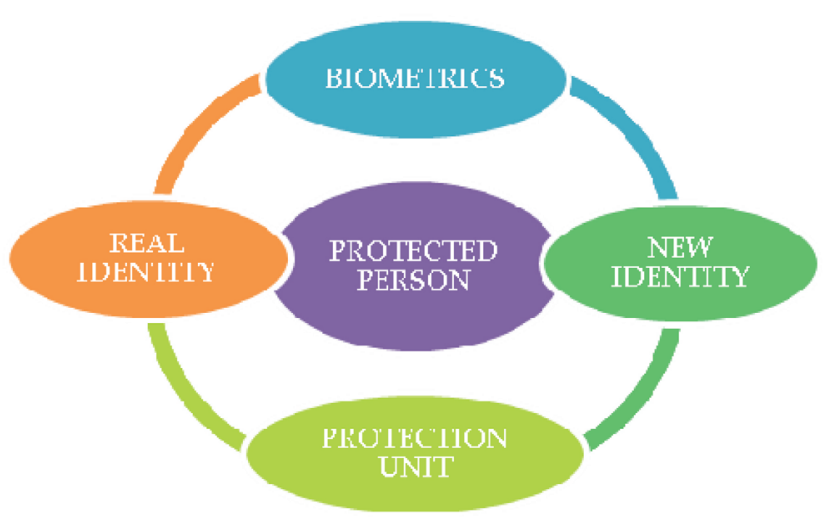

Fig. 2: Relation between the original and new identities

Given this nature of biometric data, the challenges it presents can be addressed using organisational and technical approaches. Primarily, this relates to addressing the need to exclude protected persons from the usual databases containing information on other members of the public and creating separate databases on a regional, national and international scale to enable better controlled governance over biometric data of protected persons. From a legal perspective, this is achievable, given that the laws governing the protection of criminal offenders, on a national level, allow the protection unit to seek assistance and cooperation from all available government bodies, obligating them to meet the protection unit's requirements, to aid an effective and successful execution of the protection programme.

\section{Conslusion}

The protection of persons willing to give evidence before courts is of great priority in ensuring an effective fight against organised crime and violations of international human rights. However, after the Law on protection programme of participants in criminal proceedings, all the legal requirements for effective implementation and enforcement of this Institute have been fulfilled - witness protection in criminal proceedings, in the case of offenses of organized crime, terrorism or war crimes. This paper describes the legal regulations and obligations surrounding the protection of witnesses on a regional, national, European and international scales, as well as describing the key elements of the protection programme and its execution. In addition, an insight is given into the protective measures, with particular focus on identity management. Emphasis is given to the challenges faced by the programme and the management of identities, as a result of introducing biometric identification parameters. As biometric identification gains increased presence in society, it simultaneously threatens the integrity of the current witness protection programme and identity management methods, creating a greater need for a fast and effective advancement in these management techniques. The paper suggests one possible method of achieving this, based on hierarchical governance over biometric data, providing supreme control over biometric links between previous and newly assumed identities of protected persons. Based on the findings, it can be concluded that there is a serious need to further investigate solutions to challenges faced by the witness protection programme as these are still a series of unanswered questions as to the best approach to addressing these issues.

\section{ACKNOWLEDGEMENT}

This work is a part of the project Implementation Multimodal Biometrics in Identity Management, granted by the Ministry of Science and Technological Development of Serbia, TR-32013. 


\section{REFERENCES}

[1] Biometrics and Management Identity, (2012). Retrieved from http://www.Biometrics_and_identity_management_schematic, accessed 10/13/2012,

[2] Criminal Law Convention on Corruption of 27/01/1999.

[3] Dandurand, Y., Farr, K. (2010). A Review of Selected Witness Protection Programs, Her Majesty the Queen in Right of Canada, Report No. 001, 2010, Canada

[4] Dessimoz, D., Richiardi, J., Champod, C., Drygajlo, A. (2007). Multimodal biometrics for identity documents, Forensic Science International 167

[5] Douglas A. K. (2004). Witness Protection Program is critical weapon in the war of crime, The FBI Law Enforcement Bulletin, No.5, Vol. 74, USA

[6] Ilic, G., Majic, M., Ilic, B. (2006). Comments to the law on the protection program of participants in criminal proceedings, Belgrade (in Serbian)

[7] International Criminal Tribunal for the Former Yugoslavia (ICTY,1993). Established under UN Security Council resolution no. 827 of 25 May 1993

[8] Law on Protection Program in Criminal Procedure Code, (2005). Official Gazette of R. Serbia No. 85/2005 (in Serbian)

[9] Paunovic, S., Starcevic, D. (2011). Identity management and electronic document-based biometric identity, Proc. of SYMOPIS 2011, Zlatibor, Serbia, September 2011. (in Serbian)

[10] Recommendation, (1991). Concerning sexual exploitation of children and youth exposure to pornography, prostitution and smuggling, $N^{\circ} \mathrm{R}(91) 11,19 / 09 / 1991$.

[11] Recommendation, (1997). Labelled $N^{\circ} R(97) 13$ concerning intimidation of witnesses and the rights of defence, made at the $600^{\text {th }}$ session of the Ministers' Deputies June 1997.

[12] Recommendation, (1996). Criminal policy in Europe during the change, $N^{\circ} R$ (96) 8, of 5 . September 1996.

[13] Recommendation, (1984). Domestic Violence, $N^{\circ} \mathrm{R}(84) 4$, of 28. February 1984.,

[14] Recommendation, (1987). Protection and victim assistance, $N^{\circ} \mathrm{R}(87) 21$, of 17. September 1987.

[15] Recommendation, (2005). Rec. 9 on the protection of witnesses and collaborators, adopted by the Committee of Ministers of 20 April 2005. on the 924th Meeting of Deputy Ministers,

[16] The Statute of the International Criminal Court (ICC, 2002). Entered into force on 1 July, 2002,

[17] United Nations Convention against Transnational Organized Crime (UNCATOC, 2003). With additional protocols, which came into force on 29/09/2003.

[18] United Nations Office, (2008). On Drugs and Crime Vienna Good practices for the protection of witnesses in criminal proceedings involving organized crime, N.York, 2008.

[19] US Marshal Service, (2012). Retrieved from http://www.usmarshals.gov/duties/factsheets/witsec2011.html, accessed 10/13/2012

[20] US Marshal Service, (2012). Retrieved from http://www.usmarshals.gov/witsec/index.html, accessed $10 / 13 / 2012$ 


\section{|||||||||||||||||||||||||||||||||| $\mid$ asoutrosenter}

\section{Sasa Paunovic \\ Ministry of Interior, Republic of Serbia sasa.paunovic@mup.gov.rs}

Sasa Paunovic was born in Valjevo on 21 July 1971. He received his BS in management and MS in multimedia communications and public relations from the University of Belgrade, Faculty of Organizational Sciences. Sasa Paunovic is currently a doctoral student at the University of Belgrade. Mr. Paunovic is the author of several works on the subject of biometrics, identity management and protection of participants in criminal proceedings. He is employed by the Ministry of Interior of the Republic of Serbia.

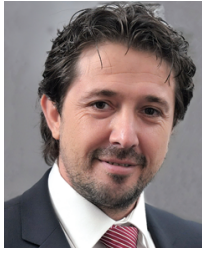

Dusan Starcevic University of Belgrade, Faculty of Organizational Sciences dusan.starcevic@fon.bg.ac.rs

Dusan Starcevic is a professor at the Faculty of organizational sciences University of Belgrade. His main research interests include human-computer interaction, distributed information systems, and multimedia. Starcevic received his BS and MS in electrical engineering and his PhD in information systems from the University of Belgrade.

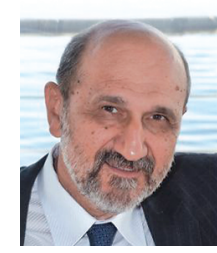

Lazar Nesic Ministry of Interior, Republic of Serbia lazar.nesic@mup.gov.rs

Lazar Nesic was born on $4^{\text {th }}$ of March 1969. He graduated in February 1996 and received an engineer's degree in electrical engineering. He has been continuously employed with the Ministry of Interior of the Republic of Serbia since $3^{\text {rd }}$ of June 1996. In 1998 he became a forensic expert in arson and explosion examination within the National Forensic Centre. In 2006 he was appointed the Head of the National Forensic Centre. Lazar Nesic is fluent in English, German and Hungarian. 